\title{
Carrots and Sticks: Incentives and Regulations for Herbicide Resistance Management and Changing Behavior
}

\author{
Michael Barrett, John Soteres, and David Shaw*
}

Although the problem of herbicide resistance is not new, the widespread evolution of glyphosate resistance in weed species such as Palmer amaranth (Amaranthus palmeri S. Wats.), common waterhemp (Amaranthus rudis Sauer), and kochia [Kochia scoparia (L.) Schrad.] raised awareness throughout the agricultural community of herbicide resistance as a problem. Glyphosate-resistant weeds resulted in the loss of a simple, single herbicide option to control a wide spectrum of weeds that gave efficacious and economical weed management in corn (Zea mays L.), soybean [Glycine max (L.) Merr.], and cotton (Gossypium hirsutum L.) crops engineered for tolerance to this herbicide and planted over widespread areas of the South and Midwest of the United States. Beyond these crops, glyphosate is used for vegetation management in other cropping systems and in noncrop areas across the United States, and resistance to this herbicide threatens its continued utility in all of these situations. This, combined with the development of multiple herbicide-resistant weeds and the lack of commercialization of herbicides with new mechanisms of action over the past years (Duke 2012), caused the weed science community to realize that stewardship of existing herbicide resources, extending their useful life as long as possible, is imperative. Further, while additional herbicide tolerance traits are being incorporated into crops, weed management in these crops will still be based upon using existing, old, herbicide chemistries.

The concerted action of players across the agricultural community will be required to preserve the utility of existing herbicides, which can be considered a common resource. Herbicide resistance is also considered a "wicked problem" by social

\footnotetext{
DOI: $10.1614 / W S-D-15-00171.1$

* First author: Professor, Department of Plant and Soil Sciences, University of Kentucky, Lexington, KY 40546; second author: Global Weed Resistance Lead (retired), Monsanto Company, St. Louis, MO 63167; third author: Professor and Vice-President for Research and Development, Mississippi State University, Starkville, MS 39762. Corresponding author's E-mail: mbarrett@uky.edu
}

scientists (Ervin and Jussaume 2014). A fundamental reason herbicide resistance is a "wicked problem" is the mobility of weeds, and resistance traits, so the problem is not confined to one grower's property (Beckie et al. 2015; Borger et al. 2007; Dauer et al. 2006; Diggle and Neve 2001; Norsworthy et al. 2009; Shaner and Beckie 2014; Shields et al. 2006; Sosnoskie et al. 2012). As such, it has no single solution and is, essentially, unsolvable because the threat of resistance evolving remains while herbicides are being used to manage weeds. However, effective incentives and regulations ("carrots and sticks") can help control or slow resistance evolution.

As discussed at the Second Herbicide Resistance Summit (WSSA 2014), dialog between the weed science community and social scientists has developed the notion that resistance is not a technology problem per se, but rather a result of human behavior while using the technology. The repeated use of a weed management strategy lacking in diversity of tactics over broad geographic areas places intense selection pressure on weed populations to evolve resistance. There is a great deal of information on how weed management can be diversified to delay resistance (Norsworthy et al. 2012). However, these best management practices (BMPs) are not being adopted quickly or widely enough to insure that resistance will not continue to evolve and spread, despite extensive educational programs on herbicide resistance management in both the public and private sectors.

If prevention and management of herbicideresistant weed populations is to change, behaviors must change throughout the agricultural community and in how farmers manage weeds. Behavior change in agriculture can come from complex and interacting sources of motivation, such as the community, economics, and education. The analogy of a "thousand little hammers" is often used to describe a diversified weed management strategy that does not rely on one management tactic. This same concept can be applied to an approach to change behavior to better manage herbicide resis- 
tance. Thus, even though we contend that herbicide resistance is a wicked problem, we propose that a people-centered approach that combines a community-based component within a supportive framework offers the best chances for progress. A community-based and community-wide approach to managing herbicide resistance is necessary because of the real and perceived mobility of resistant weeds (Borger et al. 2007; Dauer et al. 2006; Diggle and Neve 2001; Norsworthy et al. 2009; Shields et al. 2006; Sosnoskie et al. 2012). Because of this, both weed and social scientists are acknowledging common pool problems and the need for regional approaches for herbicide resistance management (Beckie et al. 2015; Ervin and Jussaume 2014; Shaner and Beckie 2014). We believe that education, technical assistance, incentives, and regulation will be parts of the needed framework. We propose that incentives and regulations can contribute to changing the future of herbicide resistance. In this paper we discuss ideas and potential roles for incentives and regulation in this context. We suggest that incentives should emphasize proactive BMPs, to combat resistance before it occurs. Regulation, on the other hand, could be used to promote both proactive and reactive actions. Although herbicide resistance is a global problem, the focus of this paper is restricted to how incentives and regulation could be used to change behavior in the United States. However, the examples and concepts discussed here could also be useful in other countries struggling with this problem.

\section{Incentives for Herbicide Resistance Management Adoption}

Why incentives? Simply put, rewards can change behavior. Incentives can be effective in moving the needle on herbicide resistance BMP adoption and practice by encouraging and rewarding decisions that weed scientists know will prevent or delay herbicide resistance evolution. Incentives are needed to encourage changes in growers' behavior because some BMPs are seen as being more expensive than current practice in the short run (Brewer and Goodall 2012; Livingston et al. 2015; Riar et al. 2013; Weirich et al. 2011). Barriers to implementing key BMPs, such as increasing the diversity of herbicides used and including more nonchemical practices to prevent the evolution of herbicide resistance, are primarily economic in the form of higher costs, even though other factors such as convenience, time requirements, and labor availability can play significant roles. Economic incentives can encourage growers to implement BMPs by overcoming the perceived or real initial cost of BMP implementation, mitigating the uncertainty of costs associated with "doing something different," and improving the acceptance of nonmonetary costs of using herbicide resistance BMPs. Financial incentive programs to encourage implementation of herbicide resistance management (HRM) best practices can be public or private.

Examples of government incentive programs include those for natural resource conservation (Brewer and Goodell 2012; Segerson 2013) and insect pest management (Brewer and Goodell 2012). Additionally, an often-cited example of a nonfinancial incentive is the avoidance of government regulation. Fear of government regulation can motivate all the players involved in HRM, from industry registrants to farmers. Incentive programs can also be defined in terms of voluntary actions encouraged and promoted by government agencies or implemented by the private sector, independent of government involvement. These voluntary incentives in agriculture can come in a variety of forms including education, technical advice, or monetary support (Ervin 2013).

Voluntary approaches have been used in a variety of contexts and for a variety of purposes in agriculture, including voluntary conservation programs and product labeling (Segerson 2013). Segerson defined voluntary approaches as programs and initiatives in which parties voluntarily agree to participate, rather than being legally required or forced to do so. Additionally, Segerson summarized general principles for a voluntary approach to be successful: it must provide sufficiently strong participation incentives, have clearly identified standards for behavior or performance and outcomes that can be monitored, and noncompliance must be detected and result in credible consequences. The program's design, and whether it is practiceor performance-based, will determine the ease and cost of monitoring and enforcement. Drawing parallels to our understanding of herbicide resistance management indicates that many of the conditions of success as defined by Segerson could be met and, therefore, this could be a viable approach to herbicide resistance management.

There are also parallels between promotion of widespread adoption of HRM programs and moving the practice of integrated pest management (IPM) from field-scale to regional-level adoption. 
Brewer and Goodell (2012) outlined those for IPM; some of their key findings were: (1) implementation of IPM was most effective where support of public agencies was combined with private investment; (2) most successful area-wide efforts were focused on a single pest (although this complicates application to weed management); and (3) a driving force of successful area-wide IPM programs was the recognition that economical pest management was dependent on everyone working together. This emphasizes the need for community-wide involvement and acceptance by all stakeholders. Successfully connecting implementation of IPM with environmental objectives has been most apparent when (1) the risks are high, (2) relevant technologies are available, and (3) financial incentives are flexible and reasonable to address locally relevant issues that resonate with farmers. In summary, voluntarily implemented programs can be successful if certain conditions, such as sufficient funding for incentives or a credible threat of regulation, exist.

Present and Possible Future Incentives for Herbicide Resistance Management. The potential incentive and regulation community for managing herbicide resistance can be separated into government, industry, and commodity group sectors. Federal agencies in the United States that are or could be involved in incentives or regulations for herbicide resistance management include the Natural Resources Conservation Service (NRCS) of the U.S. Department of Agriculture (USDA), the Risk Management Agency (RMA) of the USDA, the Animal and Plant Health Inspection Service (APHIS) of the USDA, and the Environmental Protection Agency-Office of Pesticide Programs (EPA-OPP). The agrochemical industry, commodity groups, and, potentially others such as state agencies, Farm Bureau, or farmer cooperatives, could also offer incentives for HRM adoption.

The NRCS is the federal agency that works with landowners to help them conserve, maintain, and improve natural resources. Voluntary conservation practices, technical assistance, and incentive-based programs are some of the Agency emphases (USDA 2016 a,b). Two NRCS programs already in place to incentivize herbicide resistance management under the Conservation Stewardship Program (CSP) are the Plant Enhancement Activity (PLT) 19, "Herbicide-resistant weed management," and the PLT20, "High-residue cover crop or mixtures of high-residue cover crops for weed suppression and soil health" (USDA 2016c). These are both national programs offered for adoption by local conservation districts; these programs provide annual and supplement payments through 5-yr contracts (USDA 2016d). PLT19, in particular, requires adoption of a number of the recognized herbicide resistance BMPs (Norsworthy et al. 2012) to qualify. The NRCS Environmental Quality Incentives Program (EQIP, USDA 2016e) has an option under the Conservation Activity Plan area (CAP, \#154 [USDA 2016f]) for developing Integrated Pest Management Herbicide Resistance Weed Conservation plans. The objective of this program is to identify changes in herbicide use for controlling weeds on cropland, including managing those resistant to herbicides. Depending on the size of the farm, 2015 payment rates for the labor to develop a resistance management plan range from $\$ 1,652$ to $\$ 3,966 \mathrm{farm}^{-1}$. Both these programs have requirements for documentation to allow for monitoring compliance. The Conservation Innovation Grants (CIG) is another program within NRCS that could be used to foster adoption of herbicide resistance management practices. The objective of the CIG program is to "stimulate the development and adoption of innovative conservation approaches and technologies" (USDA 2016g), and the 2015 call for proposals for the CIG program included language to encourage submission of proposals dealing with herbicide resistance. One recommendation would be for wider and more consistent emphasis on NRCS programs for herbicide resistance across states and counties. Although these programs are developed at the national level, individual states and, especially, county level boards of non-NRCS personnel determine which programs will actually be funded in any one area. Consequently, these programs are not uniformly available at the county level, and although local control means the most appropriate programs can be selected for a county, local NRCS staff can administer programs unevenly. A case in point is farmers' desire to use tillage to manage resistance or diversify a weed management program being in conflict with NRCS programs to minimize or eliminate tillage. However, conservation dollar amounts are relatively small (especially relative to crop insurance subsidies) and are not increasing (Claasen 2014; Table 1 and Figures 1 and 2). Therefore, more funding will be required for conservation programs in general and for herbicide resistance management programs specifically if HRM is to be widely incentivized.

The USDA Risk Management Agency (RMA) is another federal agency with potential to encourage

Barrett et al.: Incentives/regulations for HRM • 
Table 1. Comparison of corn crop insurance support vs. conservation programs (CAP and EQIP) subsidies for major U.S. cornproducing states. ${ }^{a}$

\begin{tabular}{|c|c|c|c|c|c|}
\hline \multirow[b]{3}{*}{ State } & \multicolumn{2}{|c|}{ Crop insurance } & & & \\
\hline & \multicolumn{2}{|c|}{ Corn program } & \multicolumn{3}{|c|}{ All programs } \\
\hline & $\begin{array}{l}\text { Acres } \\
(\%)\end{array}$ & $\begin{array}{c}\text { Subsidies } \\
\text { (millions \$) }\end{array}$ & $\begin{array}{c}\text { Liabilities } \\
\text { (millions \$) }\end{array}$ & $\begin{array}{l}\text { CAP subsidies } \\
\text { (millions \$) }\end{array}$ & $\begin{array}{l}\text { EQIP subsidies } \\
\text { (millions \$) }\end{array}$ \\
\hline Iowa & 92 & 364 & 10,433 & $\$ 41$ & 34 \\
\hline Illinois & 79 & 293 & 8,398 & 18 & 19 \\
\hline Nebraska & 91 & 256 & 5,931 & 46 & 33 \\
\hline Minnesota & 94 & 287 & 6,086 & 59 & 30 \\
\hline Indiana & 74 & 146 & 3,603 & 8 & 22 \\
\hline South Dakota & 97 & 266 & 3,071 & 38 & 23 \\
\hline Kansas & 90 & 137 & 2,126 & 44 & 32 \\
\hline Wisconsin & 70 & 122 & 1,896 & 15 & 33 \\
\hline Ohio & 77 & 99 & 2,157 & 4 & 26 \\
\hline Missouri & 85 & 119 & 1,649 & 28 & 39 \\
\hline North Dakota & $\sim 100$ & 182 & 1,660 & 51 & 21 \\
\hline
\end{tabular}

${ }^{a}$ Abbreviations: CAP, Conservation Activity Plan Program; EQIP, Environmental Quality Incentives Program. Both programs are administered by the Natural Resources Conservation Service.

${ }^{\mathrm{b}}$ Only 920 out of 24,362,248 contracted acres received assistance to develop an HRM plan.

herbicide resistance management. RMA, through its Federal Crop Insurance Corporation, is the source of crop insurance for farmers and ranchers. Insurance companies in the private sector sell and service the crop insurance policies, but RMA helps develop and approve the premium rates. In that role, RMA could incentivize herbicide resistance management as a good agronomic practice to avoid crop failures. Policy premiums, like lower health insurance rates for nonsmokers and auto insurance rates for those without traffic citations, could be lower for those practicing BMPs for herbicide resistance management. For example, RMA approved a program for a premium rate reduction if

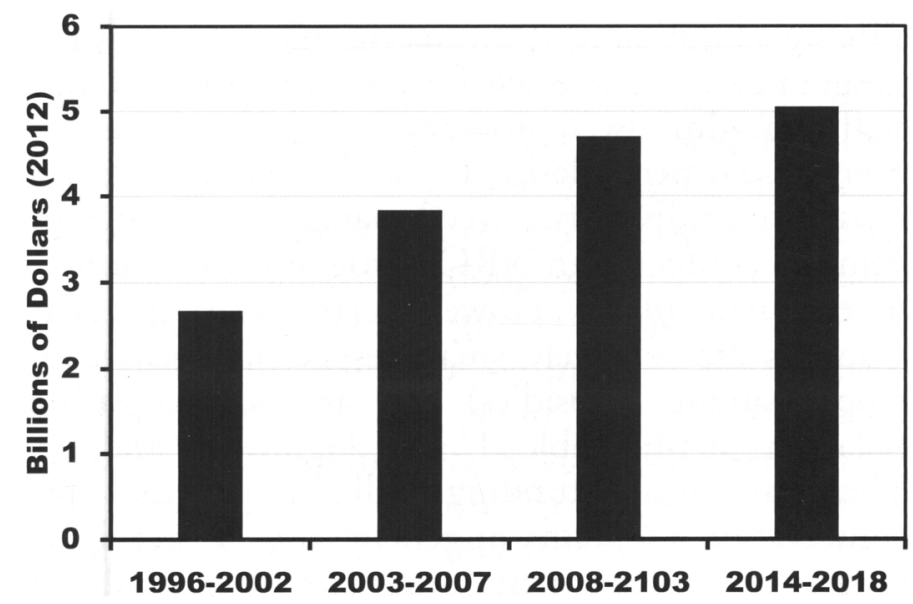

Figure 1. Historical and projected average annual spending for major USDA conservation programs. Adapted from Claasen (2014). specific triple-stack transgenic crop varieties were planted instead of conventional hybrids (USDA 2016h). Crop insurance policies already contain references to "Good Farming Practices" recognized by farming experts to be suited to crop production in the area, and "Sustainable Farming Practices" generally recognized to conserve or enhance natural resources environment (Anonymous 2014); herbicide resistance BMPs could be similarly emphasized. However, because current RMA policy is to insure against yield loss caused by weeds, it might actually discourage management of resistance because growers are not penalized by yield losses due to resistance (D Ervin, personal communication). The RMA philosophy would need to change to make growers more responsible for avoiding yield losses due to

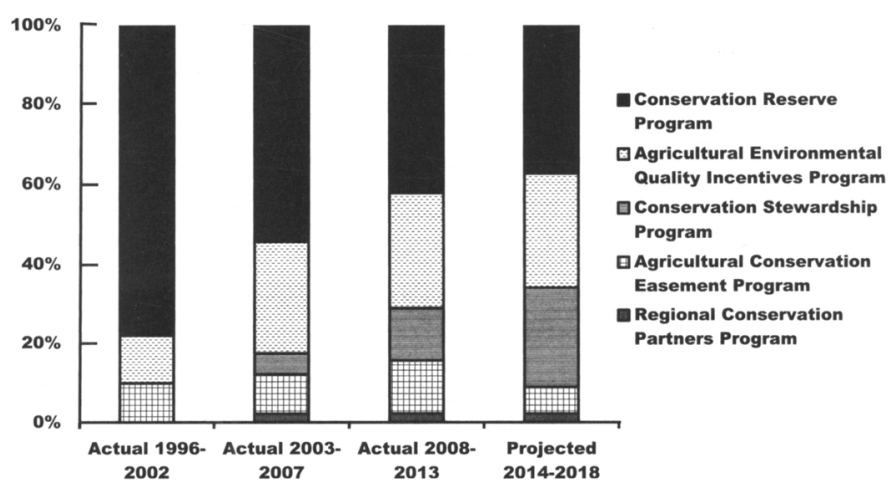

Figure 2. Proportion of spending on major conservation programs in the 2014 and previous farm acts. Adapted from Claasen (2014). 
resistance, rather than reimbursing them when the losses occur.

Industry can incentivize diversity in weed management practices through marketing approaches. One such example is Monsanto's "Roundup Ready PLUS ${ }^{\circledR}$ " platform (Volkmann 2010) that provides training and education, recommendations for weed management, and incentives for corn, soybean, and cotton farmers. This platform has existed in various forms since 2008 (Monsanto 2015) and grower participation has increased each year ( $M$ Horak, personal communication). A corn or soybean farmer wishing to take advantage of the incentives qualifies by using a residual herbicide and purchasing one of the Roundup Agricultural Brand herbicides. Cotton growers participate by purchasing cotton with the Roundup Ready Flex or Roundup Ready Xtend Flex trait and purchasing one or more of the recommended residual herbicides. To receive the incentive, a grower purchases residual, preemergence, or postemergence herbicides from a list of qualified products from a participating Monsanto dealer and applies them at recommended rates. The list of qualified herbicides contains a wide range of products available from several manufacturers. Monsanto then sends a dual party check made out to both the grower and the retailer to the retailer. This allows the retailer a chance to reinforce the good decisions and practices that led to the incentive being earned by the grower. The check is then endorsed by both parties and the grower receives compensation. In some instances, the retailer might provide a discount to the grower up front and then retain the money if they have made such arrangements with the grower. However, this is not recommended or endorsed by Monsanto. The amount of the incentive is tied to the specific Roundup Agricultural herbicide brand. For example, in 2015, if a farmer used an approved rate per acre of Roundup and a qualified herbicide, Monsanto provided a payment of $\$ 0.50$ to $\$ 4.60$ $\operatorname{acre}^{-1}\left(\$ 1.24\right.$ to $\left.\$ 11.37 \mathrm{ha}^{-1}\right)$ or more, depending on the crop being grown and the herbicides used. The objective of this approach is to change grower behavior by providing incentives to add both soilapplied and POST herbicides to the Roundup Ready cropping system to diversify the mechanisms of action being used in any one field. Continuation of the Roundup Ready Plus program is under annual evaluation by Monsanto (M Horak, personal communication). This is understandable because incentives are rarely permanent in nature, and usually should not be so. Annual costs for the program in 2011 were estimated to be $\$ 39$ million, even if only $10 \%$ of farmers using Roundup Ready ${ }^{\circledR}$ cotton and soybean received maximum rebate levels (Mitchell 2011). Although several factors are likely involved, including attempts to control glyphosateresistant weeds and the availability of prepackaged mixes of glyphosate with other herbicides, the use of herbicides in conjunction with glyphosate has increased between 2005 and 2010 in corn and between 2006 and 2012 for soybean (Livingston et al. 2015). Over the same periods, the use of glyphosate alone declined in soybean and remained relatively constant in corn (Livingston et al. 2015).

Finding ways to incentivize the entire supply chain, including a company's sales force, to promote herbicide resistance BMPs will require creativity on the part of industry. In the example above, both the grower and the retailer receive a reward for using and selling certain products, some of which are not Monsanto herbicides. Some companies are actively educating their sale force on BMPs for herbicide resistance management, although understandably with a focus on herbicide use. But, if the bottom line for a sales person is the total amount of their products sold, there is little incentive to promote competitive products or nonherbicidal practices that are useful for resistance BMPs. The adoption of the Roundup Ready technology might have been slower and cases of glyphosate resistance fewer if the technology had been promoted as a package with other herbicides rather than a glyphosate-only system, but what incentive would a sales force have to do that? Even though they might sell a larger amount over a longer period if resistance management prolongs the efficacy of their products, future rewards will be discounted over near-term sales.

Managing resistance through diversity of herbicide use is hampered by the lack of new herbicide mechanisms of actions commercialized over the past $30 \mathrm{yr}$. There are a number of reasons for this (Duke 2012), but one part of a solution could be to change the patent life for a new herbicide. Although a U.S. utility patent is nominally in effect for $20 \mathrm{yr}$, in practice the patent only protects a company from competition from generic versions of the same active ingredient for the period of time after EPAOPP approves registration of a product. This can take 6 or more yr, which significantly reduces the useful life of the patent. If the patent clock did not begin until a new herbicide was approved, perhaps only applied to new herbicides with a new mechanism of action (MOA), there would be a longer time available for a company to recoup the

Barrett et al.: Incentives/regulations for HRM • 
herbicide discovery and development costs. This could decrease pressure to over-market a new product and could make a company more receptive to restrictions on use of the new herbicide as part of a resistance management strategy. Of course, this patent life alteration is not EPA's decision to make and would require a change in U.S. patent law. However, there are precedents: the Drug Price Competition and Patent Term Restoration Act (Public Law 98-417), informally known as the Hatch-Waxman Act, makes patent exceptions available to pharmaceutical companies, permitting exclusive marketing of a new drug to allow for the time it takes for approval by the Federal Drug Administration.

Caveats for Incentives. Based on the finding of Brewer and Goodell (2012) that implementation of IPM was most effective when support of public agencies was combined with private investment, it would seem that programs such as those of NRCS, particularly those promoting nonherbicidal strategies for weed management, combined with industry programs similar to Monsanto's “Roundup Ready PLUS ${ }^{\circledR}$ " program to encourage diversity in herbicide use, could effectively promote HRM. The objective of these incentives is to overcome the initial reluctance of farmers, based on higher perceived cost, to adopt herbicide resistance BMPs. It is hoped that, after initial use, the longer-term use of the practice will be continued based on clearly observed advantages by the farmer. However, this can be a difficult objective to achieve; incentives might not guarantee long-term adoption of resistance BPMs, particularly if neighbors are not also practicing BMPs. If long-term use of resistance BMPs requires continued incentives, they become subsidies, and the benefit to society vs. the cost will need careful examination. In addition, systems will be needed to measure HRM adoption and continued use to know if incentives are being effective.

Another consideration is targeting of incentives for herbicide resistance BMP adoption to those cropping systems, environments, and weed complexes deemed most prone to herbicide resistance evolution. Arbuckle (2013) found that farmers are willing to accept a shift to targeted incentives for conservation. Past history can guide discussion within the weed science community to identify areas to target based on herbicides' mechanisms of action, cropping systems, and weed species with a history of or potential for evolving resistance.
Characteristics of individual farmers will also determine the effectiveness of incentives to promote long-term herbicide resistance BMP adoption. Farmers motivated by feelings for environmental stewardship or responsibility to others are more likely to adopt conservation practices than those farmers primarily concerned with their farm as a for-profit business enterprise (Reimer et al. 2011, 2012). This argues for the importance of community in developing a sense of practicing resistance BMPs for the good of all (Sheeder and Lynne 2011).

Finally, incentive programs must be carefully designed with a clearly defined structure to be effective and efficient. There needs to be an authority to design and monitor the program, such as the NRCS and Monsanto examples given previously, but other authorities could be farmer organizations or more local groups such as farmer cooperatives. Partnerships between public and private sectors are another possibility. Programs must be flexible in order to accommodate participant diversity, reduce costs, and increase adoption, and program effectiveness should be monitored. Incentives should be targeted to overcome specific barriers such as input cost, coupled with educational programs, and should not be offered for practices farmers would adopt anyway. Even then, incentive programs are not free from potential problems and can be "top down" systems at taxpayers' cost.

\section{Regulation for HRM Adoption}

It is a common belief that those associated with production agriculture, whether the agrichemical industry, farmers, consultants, or others, do not want additional government regulation of their operations or industry. During the introduction of crops engineered to express Bacillus thuringiensis (Bt) toxins, it was argued by Thompson and Head (2001) that regulations requiring insect resistance management plans would be impractical and inefficient in achieving their objective: these authors saw regulation as discouraging innovation and lacking the flexibility to address and adapt to localized situations. Rather than regulation, they suggested that EPA should encourage voluntary resistance management plans and educational programs on the use of IPM and insect resistance management (IRM). Despite these arguments and suggestions, the EPA-OPP, through its Biopesticides and Pollution Prevention Division, implemented a mandatory monitoring and reporting 
system, including the use of insect refuges, for $\mathrm{Bt}$ crops (EPA 2016a). This EPA requirement for farmers to plant non-Bt refuges, and for registrants to oversee insect-resistant management plans, is a precedent for the Agency to regulate herbicide resistance management. The association of the $\mathrm{Bt}$ requirements with a legally binding seed agreement for the genetically modified crop with the Bt trait makes this program relatively easy to administer and monitor. Before a grower can purchase seed engineered with the Bt trait, they must first agree to and sign a technology use agreement or obtain a technology use license (the exact term varies between seed providers) which stipulates conditions for use of the seed, including resistance management, and penalties for noncompliance. Later considerations of the impact of the regulation of Bt crops (Matten et al. 2008) suggested it was generally positive, but that the cost of regulation could be a hindrance in developing these traits for minor crops. Surveys of farmers show a 70 to $90 \%$ compliance rate with the $\mathrm{Bt}$ trait IRM requirements (Alexander 2007; Goldberger et al. 2005). However, what is also telling is that, although farmers understand that refuges are effective in managing insect resistance to $\mathrm{Bt}$, about a third would not have used them unless they were required to do so (Alexander 2007). In a survey conducted in 2003 to 2004, farmers gave as a reason for not planting a refuge the competitive disadvantage they had compared to those who did not plant refuges (Alexander 2007). A common theme in many reports of $\mathrm{Bt}$ refuge requirements was that training and education explaining the benefits and need for the requirements, were critical to the implementation of BMPs. In summary, mandatory requirements were insufficient to ensure total BMP compliance, but the regulation was critical to the establishment of refuges. Regulation can have a role to play in resistance management.

The EPA and Herbicide Resistance Management. Two federal agencies have a potential role in regulating management of herbicide resistance: the U.S. Department of Agriculture-Animal and Plant Health Inspection Service (USDA-APHIS) and the Environmental Protection Agency-Office of Pesticide Programs (EPA-OPP). USDA-APHIS, through its Biotechnology Regulatory Services program, regulates under the authority of the Plant Protection Act the introduction of certain genetically engineered organisms that might pose a risk to plant health, including some new herbicide-tolerant plants. USDA-APHIS also assesses the environ- mental impacts of releasing these plants into the environment, as required under the regulations implementing the National Environmental Policy Act. EPA-OPP, through its risk assessment and herbicide label approval processes, determines whether a herbicide can be safely used when the label instructions are followed. Despite the complementary responsibilities of the two agencies, EPA-OPP has the dominant role in regulating herbicides associated with genetically engineered crops, as well as those that are not.

Two guiding principles from the Federal Insecticide, Fungicide, and Rodenticide Act (FIFRA) in EPA-OPP's consideration of herbicide resistance are that a pesticide cannot cause undue environmental damage, and that the agency has a responsibility to protect the public good. In this case, a herbicide or herbicide mechanism of action can be interpreted as affecting a public good, not just something affecting individual farmers: one could argue that the loss of effective herbicides diminishes our ability for economical production of sufficient food. The cost of weed management has increased since the evolution of glyphosate resistance (Housenger 2014). In addition, management of herbicide-resistant weeds has led to the use of greater total amounts of herbicides, increasing the environmental risk of weed management systems ( Becker, personal communication). As part of the current regulations concerning resistance, occurrences of new biotypes of weed species that are confirmed to be resistant to herbicide chemistry are reported under adverse effects reporting regulations, FIFRA section 6(a)(2). Although EPA holds that this responsibility to protect the public gives it the authority to regulate resistance management (Matten 1997), others (Thompson and Head 2001) suggested this is a broader interpretation of the benefits section of FIFRA and it was not used until $\mathrm{Bt}$ crops were developed. Although this argument might persist, the $\mathrm{Bt}$ IRM requirements remain in effect and are, thus, a validation that EPA has the authority to regulate to encourage resistant management.

Among the regulatory tools available to EPAOPP are mandates applicable to herbicide registrants and farmers through use restrictions or directions on product labels. EPA-OPP can also require registrants to perform specific activities, such as developing and submitting HRM plans, conducting educational programs, monitoring for resistance in specified ways, and developing resistance mitigation plans. Additionally, registrants can

Barrett et al.: Incentives/regulations for HRM • 
be required to put specific notices and other information on product labels, such as herbicide MOA group numbers as described by Shaner (2014).

The primary focus of educational and other efforts concerning herbicide resistance is proactive prevention of further resistance evolution and spread (i.e., implementing steps before resistance becomes established or first evolves in an area). However, reactive mitigation of resistance, once identified, might be just as important to prevent further widespread occurrence of resistance, especially to new herbicide products. The most prominent example of mandated requirements to address pesticide resistance in agriculture, the previously mentioned regulation of $\mathrm{Bt}$ crops, contains both proactive and reactive elements. There are registrant and EPA-OPP requirements for farmers to include a non-Bt refuge when planting a genetically modified crop containing a Bt protein trait (proactive resistance management). In addition, registrants make on-farm assessments of refuge compliance and investigate claims of nonperformance (reactive resistance management).

To date, no government agency, in the United States or elsewhere in the world, has chosen to regulate herbicide use, rates, or frequency of application as part of a resistance management program. It has been questioned whether EPA has the authority to prescribe herbicide use, rates, or frequency of application for the proactive management of resistance management. However, EPA already, for other risk considerations, places these same limitations on any pesticide use, so the answer would seem to be "yes they can." Pesticide use can also be limited for resistance management without the limits being imposed by the EPA. For example, industry has placed self-imposed limits on fungicide use for resistance management (Brent and Hollomon 2007). These restrictions can be found on many fungicide labels and are generally considered to have been effective, inexpensive, and accepted by growers. Housenger (2014) pointed out this difference between herbicides and fungicides or insecticides in the industry approach to resistance management. The United States has the greatest number of herbicide resistant weed biotypes (Heap 2016), and herbicides currently have little or no use restrictions for resistance management, whereas other pesticides do have use limits for this purpose. Recently, an industry group proposed herbicide use restrictions similar to those for fungicides for the hydroxyphenylpyruvate dioxygenase (HPPD)-in- hibitor herbicides (Porpiglia et al. 2014). It might be that industry will move at least some herbicides closer to the resistance management approach for insecticides and fungicides. In addition, individual states could impose their own limitations on herbicide use; they have the authority to place restrictions on pesticides beyond what is required on the federally approved label.

In considering the relative effectiveness of EPAimposed vs. voluntary industry restrictions on herbicide use for resistance management, it is conceivable that the industry approach would actually be more closely adhered to than one mandated by the EPA. Restrictions decided upon by the EPA would not have the buy-in of the industry work force and neither they nor farmers might fully understand the value of the restrictions. Compliance could be hard to monitor and enforce if industry stakeholders did not see a role for themselves in insuring adherence. Perhaps of more concern is that restrictions decided upon at the national level, whether by EPA or industry, could limit use of other locally valid weed management options, such as alternate effective herbicides or crop rotations, or that such restrictions could cause unanticipated changes in overall farming operations. EPA-imposed restrictions on herbicide use could also be counterproductive if they cause reduced emphasis on outreach and educational programs by public or private institutions. There are multiple ways to manage resistance and, therefore, limiting options and local adaptations would be counterproductive.

Present and Possible Future Regulations for Herbicide Resistance Management. Government agencies can facilitate needed changes in farmer behavior by encouraging all registrants to provide consistent and uniform HRM messages to farmers via labels, advertising and other forms of communication. They can serve as effective catalysts for improved farmer outreach and stewardship programs by industry and academia. Currently, inclusion of resistance management and MOA grouping(s) on a herbicide label is voluntary as specified in Pesticide Registration Notice 2001-5 of June 2001 (EPA 2001). Registrants are encouraged to include both the MOA and resistance management language on herbicide (actually, all pesticide) labels when new or revised labels are submitted to EPA for review. This can be done by notification, which means an expedited label review by EPA (EPA 1998). The resistance management language can either be a standardized statement from PR 
Notice 2001-5 or language developed by the registrant. If only the resistance management language and MOA is being added to the label, a label amendment is not required. Matten (2003) discussed the implementation of this voluntary program and indicated that MOA rotation is one of the easiest and best approaches for reducing the risk of resistance, although applications of MOA mixtures have now shown to be more effective for delaying resistance evolution (Beckie and Reboud 2009; Norsworthy et al. 2012). MOA labeling would still be critical for designing these mixtures. The U.S. policy of voluntary resistance language labeling, especially MOA labeling, contrasts with that of Australia where MOA labeling is mandatory (Australian Pesticides and Veterinary Medicines Authority 2016). Canada's Pest Management Regulatory Agency recommends, but does not require, that registrants add MOA classification and resistance management language to final product labels (Health Canada 2013).

In 2014, EPA took a first step toward more active involvement in herbicide resistant management as part of the conditions for registration of Enlist Duo (glyphosate plus 2,4-D) herbicide (EPA 2014), for use in crops genetically engineered for tolerance to these two herbicides. First, the Enlist Duo label (Dow AgroSciences 2016) contains what is perhaps the most complete and prescriptive set of herbicide resistance management material of any herbicide. Second, EPA mandated that Dow AgroSciences (DAS, the registrant for Enlist Duo) develop a Herbicide Resistance Management plan that included investigating cases of nonperformance by the herbicide and reporting to EPA annually any nonperformance cases that were deemed to be caused by "likely resistance," based upon criteria in Norsworthy et al. (2012) for scouting for early detection of lack of herbicide efficacy (nonperformance) and indicators of possible herbicide resistance. Similar guidelines, with visual examples, can be found on the WSSA website (Soteres et al. 2011). In addition, DAS must work proactively with growers to control and contain any likely resistant weeds.

Based on human health and endangered species concerns, a number of nongovernmental organizations filed suit on October 30, 2014 in the Ninth Circuit Court of Appeals (Case 14-73353) to block the registration of Enlist Duo. Later, in the course of the legal proceedings, EPA asked the court to vacate the Enlist Duo registration based upon new information (patent claims of synergism between
2,4-D and glyphosate on plant species) that had come to EPA's attention. This information called into question EPA's measures to protect endangered plant species from damage from off-site movement of Enlist Duo. Although the Ninth Circuit Court of Appeals denied the EPA's request to vacate the registration, these developments caused some in the weed science community to question whether the resistant management requirements in the Enlist Duo registration would actually be placed into practice. In addition, the limited use of Enlist Duo solely on corn in 2015 did not provide sufficient opportunity to assess how the resistance management program would operate or be perceived by farmers. However, recent presentations by EPA staff (Chism et al. 2016) and the proposed registration of dicamba on dicamba-tolerant cotton and soybean (EPA 2016b) indicate the Enlist Duo herbicide resistance management requirements have been refined and expanded and are proposed by EPA for use with all herbicides, whether a new product or one that has undergone registration re-evaluation. This would be consistent with comments made by the Director of EPA-OPP at the Second Herbicide Resistance Summit (Housenger 2014). Although the plan is currently embedded in the proposed dicamba registration, it could be submitted independently for public comment as a Pesticide Registration Notice in the near future.

The policy outlined in the dicamba proposed registration materials consists of two major parts. The first is a series of eleven recommended elements for any resistance management plan. The second part of the proposal divides herbicides among three Resistance Categories of Concern and indicates which of the eleven elements applies to each category. Low Concern herbicides are those with MOAs that have no confirmed resistant weed species in the United States. Moderate Concern herbicides are those with MOAs with a few resistant weed species in the United States, and High Concern herbicides are any new herbicide with a new or novel MOA, those intended for application to a conventionally bred or genetically engineered herbicide-tolerant crop, or those with MOAs with the most resistant weed species in the United States. High Concern herbicides require all eleven elements of the resistance management plan. Herbicides can be moved to higher categories of concern if additional resistant weed species to that MOA are identified in the United States. (EPA 2016b).

Because this EPA plan is only a proposal at the time of writing this paper, it is difficult to predict its 
final form or the impact it might have on behavior in the agricultural community and ultimately on the evolution of further herbicide resistance. However, some tentative insights can be gleaned from similarities between the Enlist Duo requirements and the dicamba proposal. First, because both the Enlist Duo and dicamba registrations include a 5-yr time limit, this will put significant pressure on the registrant to manage resistance or risk not having the registration renewed. The statement "The continued availability of this product depends on the successful management of the weed resistance program" was included on the Enlist Duo label. Second, to measure success in managing resistance and to enable earlier intervention to contain any evolving resistance, the EPA will collect data on new reports of suspected resistance and, importantly, these will be shared with the users. Although details of the collection and reporting are to be worked out, the sense is that this will increase vigilance for resistance in the agricultural community and, hopefully, contain it before it spreads. The registrant is also required to work with farmers to control any new suspected resistant weed populations and report the status of those efforts to EPA. These factors, taken together, suggest that EPA will have a more complete picture of what is happening in the field concerning resistance and will have the chance to intervene early if resistance is not being managed. In addition, the proposal contains elements (MOA labelling, BMP labelling, required educational materials, listing of individual active ingredient effectiveness against particular weed species) that weed scientists have argued for as necessary for effective education for managing herbicide resistance. Although some of this material is already present on many herbicide labels or in educational materials, consistent presence and availability of the information will improve farmer's ability to implement herbicide resistance BMPs.

What motivated EPA to take these actions? Clearly, glyphosate resistance raised the issue of herbicide resistance to unprecedented exposure, including congressional hearings (U.S. Congress 2010) and nongovernmental organization input that placed the agency under intense pressure to take action. Previous EPA policy was essentially to allow industry to self-regulate herbicide resistance management, unlike policies for $\mathrm{Bt}$ crop resistance management, and glyphosate resistance might have been too widely spread and developed before EPA could act. The monitoring program EPA has designed has the potential to prevent a similar situation from occurring again, in addition to alerting users early on if resistance is occurring. There was also clear evidence that glyphosate resistance was increasing the cost of weed management in some cropping systems (Housenger 2014; Livingston et al. 2015).

It remains to be seen whether this approach be will effective in delaying evolution of further herbicide resistance. However, it provides industry with a significant incentive to control resistance. The implied threat is that EPA will discontinue registration of herbicides if resistance becomes a major problem; rather than having to cancel the registration, EPA can simply allow it to expire. It places the burden on the company, rather than just the user, to ensure action is taken to more proactively manage resistance.

Other Governmental Regulation for Herbicide Resistance Management. Are there other roles for regulation to combat the spread of herbicide resistance? This could be a place where state seed laws or noxious weed laws could be useful. For example, Delaware added Palmer amaranth to its noxious weed list in 2012 to encourage active control of new infestations of this weed (State of Delaware 2016). The Delaware law requires that the Palmer amaranth not be allowed to exceed 24 inches in height or produce seed. Similar approaches could be used with other weed species, although some landowners might consider this to be government intrusion onto private property, and neighbors could turn against each other if one reports the presence of a noxious weed on another's property. However, this rarely happens in relation to enforcement of noxious weed regulations in Colorado and other Rocky Mountain States ( $S$ Ward, personal communication). There is also the question of who will bear the costs of control; the Delaware Plant Industries Section of the Department of Agriculture offers information on chemical and mechanical control of the weeds and has application equipment that can be borrowed free of charge. This type of program might be best suited to a case such as Palmer amaranth in Delaware, which is a weed that was not found there in the past but which is being brought in, rather than where a species is already widespread and resistant biotypes are being selected.

Another approach to regulation has been bottom-up, grower-led efforts. The best example of this is the Boll Weevil Eradication Program, which over a 40-yr period eliminated the boll weevil from the United States except in portions of 
Texas. Although USDA-APHIS was responsible for oversight and implementation, the program was put to a vote by cotton growers in each state, and only when a majority approved was the program initiated therein. Growers also could call for a vote to opt out periodically. By any metric, this program has been successful: reductions in insecticide use have occurred, profitability was increased, and yields improved (National Cotton Council 2016).

Another great example of bottom-up regulatory action is the formation of Cooperative Weed Management Areas (CWMA) that bring together all of the relevant local, state, regional, and national agencies and organizations to combat invasive plant species. An excellent description and examples can be found at Northeastern Illinois Invasive Plant Partnership (2016) and a map of CWMAs across the United States is available (North American Invasive Species Network 2016). These CWMAs recognize that a cooperative program with some level of enforcement is required to prevent introduction or spread of invasive weeds. Effective CWMAs could reduce the need for outside regulation, but also use requirements similar to those for resistance management in the EPA proposal as part of their framework to address HRM locally. The focus of current CWMAs is invasive plant management, but many of the guidelines for CWMAs, education, training, prevention and early detection, and control approaches would have direct parallels to HRM. There are already examples of locally based efforts to combat weed resistance (Barber et al. 2015).

\section{Conclusions}

In order to most effectively manage pesticide resistance, a cooperative and coordinated effort of the public and private sectors is needed. No single program or activity of government agencies, public institutions, or private industry can facilitate the needed implementation of herbicide resistance BMPs on farms. Farmers ultimately control what is done on their farms. It is incumbent upon public and private entities to provide information and justification for each recommended practice.

Most incentive programs, to date, that were designed to encourage change in farmer behavior were developed for individual fields or farms. Public financial incentives for agriculture have been most heavily used to encourage adoption of conservation BMPs for improved water and air quality, conservation of ground and surface water, reduced soil erosion and sedimentation, or improved wildlife habitat. Farmers who consider the farm as a business are less likely to adopt conservation practices than those more concerned with the environment or their responsibility to others (Reimer et al. 2012a,b). Weed management and HRM is primarily an economic, convenience, and efficacy question for most farmers. Whereas education can help establish social norms, develop networks, and raise awareness of how herbicide resistance affects the larger community, public and/or private incentives can help overcome the initial economic barriers to HRM adoption (Prokopy et al. 2008). However, paying for longterm maintenance of practices such as HRM BMPs is impractical, and would be considered a subsidy (Reimer et al. 2011, 2012).

Regulation can have a role to play in resistance management, as demonstrated by EPA requirements directed to management of insect resistance in biotech crops containing Bt traits. However, federal regulations specifying herbicide use are not a preferred uniform approach to HRM, because it would be difficult with such an approach to allow for adjustments at the local level. Local flexibility for developing and adopting specific BMPs is crucial for acceptance and effectiveness. This is difficult to obtain in broad, one-size-fits-all regulations. However, as a general approach, the effort to require detection, reporting, and control of new resistance at the earliest possible point, as outlined in the Enlist Duo registration requirements and the proposed registration of dicamba on dicambatolerant soybean and cotton, are useful additional tools for resistance management. It is important that the details of such programs be carefully considered to ensure they are practical, effective, and respect farmer privacy.

There is no one best method to mitigate herbicide resistance, and flexibility is needed to fit practices to individual farmer operations. Innovative approaches using new technologies and novel combinations of BMPs are critical as a part of the solution. Likewise, true acceptance of the BMPs will only come after farmers try them and become convinced of their merit in their operations. Thus, a combination of incentives to overcome reluctance to try unfamiliar BMPs, carefully constructed top-down regulations to discourage poor decisions in HRM, and community-based bottom-up voluntary regulatory actions will work best if they are considered together and closely coordinated.

Barrett et al.: Incentives/regulations for HRM • 
Ideally, bottom-up regulations that stem from initiatives at the private nongovernmental level, such as with national and state-level farmer groups, could establish structures to encourage adoption of BMPs without the limitations and inefficiencies of top-down regulation. However, absent clear demonstration of effective bottom-up programs, it is likely that additional regulations to deal with herbicide resistance will be proposed and instituted by EPA and, potentially, other government agencies.

\section{Acknowledgments}

The contributions of Terry Hurley and David Ervin to the writing of this paper are gratefully acknowledged. They made significant improvements to the manuscript.

\section{Literature Cited}

Alexander C (2007) Insect resistance management plans: the farmers' perspective. AgBioForum 10:33-43

Anonymous (2014) Good Farming Practice Determinations Standards Handbook. http://www.rma.usda.gov/handbooks/ 14000/2015/14060.pdf. Accessed April 18, 2016

Arbuckle JG Jr (2013) Farmer attitudes toward proactive targeting of agricultural conservation programs. Soc Nat Resour 26:625-641

Australian Pesticides and Veterinary Medicines Authority (2016) "Mode of Action" Indicator. http://apvma.gov.au/node/ 934\#Mode_of_action_indicator. Accessed April 18, 2018

Barber LT, Smith KL, Scott RC, Norsworthy JK, Vanglider AM (2015) Zero tolerance: a community-based program for glyphosate-resistant Palmer amaranth management. FSA2177-PD-3-2015N. Fayetteville, AR: University of Arkansas Cooperative Extension Service. 7 p

Beckie HJ, Gulden RH, Shaikh N, Johnson EN, Willenborg CJ, Brenzil CA, Ford G (2015) Glyphosate-resistant kochia (Kochia scoparia L. Schrad.) in Sasketchewan and Manitoba. Can J Plant Sci 95:1-5

Beckie HJ, Reboud X (2009) Selecting for weed resistance: herbicide rotation and mixture. Weed Technol 23:363-370

Borger CPD, Walsh M, Scott JK, Powles SB (2007) Tumbleweeds in the Western Australian cropping system: seed dispersal characteristics of Salsola australis. Weed Res 47:406-414

Brent KJ, Hollomon DW (2007) Fungicide Resistance in Crop Pathogens: How Can it be Managed? 2nd edn. Brussels, Belgium: Fungicide Resistance Action Committee. 56 p

Brewer MJ, Goodell PB (2012) Approaches and incentives to implement integrated pest management that addresses regional and environment issues. Annu Rev Entomol 57:41-59

Chism B, Jones A, Becker J, Yourman L, Myers C, Mallampalli N (2016) The U.S. EPA's perspective on herbicide resistance management. In Proceedings of the Weed Science Society of America 2016 Annual Meeting. http://wssaabstracts.com/ public/38/proceedings.html. Accessed April 19, 2016 [Abstract]
Dauer JT, Mortensen DA, Humston R (2006) Controlled experiments to predict horseweed (Conyza canadensis) dispersal distance. Weed Sci 54:484-489

Claasen R (2014) 2014 Farm Act Continues Most Previous Trends in Conservation. http://www.ers.usda.gov/amberwaves/2014-may/2014-farm-act-continues-most-previoustrends-in-conservation.aspx\#.VxaTeHAmUiH. Accessed April 18,2016

Diggle AJ, Neve P (2001) The population dynamics and genetics of herbicide resistance-a modeling approach. Pages 61-100 In Powles Sb, Shaner DL, eds. Herbicide Reistance and World Grains. Boca Raton, FL: CRC Press

Dow AgroSciences (2016) Enlist DuoTM Herbicide with ColexD Technology label. http://www.cdms.net/ldat/ldAEA001. pdf. Accessed April 18, 2016

Duke SO (2012) Why have no new herbicide modes of action appeared in recent years? Pest Manag Sci 68:505-512

[EPA] U.S. Environmental Protection Agency (1998) Pesticide Registration Notice (PR) 98-10: Notifications, Non-Notifications and Minor Formulation Amendments. https://www.epa. gov/sites/production/files/2014-04/documents/pr98-10.pdf. Accessed April 18, 2016

[EPA] U.S. Environmental Protection Agency (2001) Pesticide Registration (PR) Notice 2001-5: Guidance for Pesticide Registrants on Pesticide Resistance Management Labeling. https://www.epa.gov/sites/production/files/2014-04/ documents/pr2001-5.pdf. Accessed April 18, 2016

[EPA] U.S. Environmental Protection Agency (2014) Final Registration of Enlist DuoTM Herbicide. https://www.epa. gov/sites/production/files/2014-10/documents/final_ registration_-_enlist_duo.pdf. Accessed April 18, 2016

[EPA] U.S. Environmental Protection Agency (2016a) Bt Field Corn (and Popcorn) IRM Program. https://www3.epa.gov/ pesticides/biopesticides/pips/bt_corn_refuge_2006. htm\#program. Accessed April 18, 2016

[EPA] U.S. Environmental Protection Agency (2016b) Proposed Registration of Dicamba on Dicamba-Tolerant Cotton and Soybean. https://www.regulations.gov/\#!documentDetail; $\mathrm{D}=$ EPA-HQ-OPP-2016-0187-0016. Accessed April 18, 2016

Ervin DE (2013) Voluntary resource conservation and environmental management in agriculture and forestry. Pages 127132 in Shogren J, ed. Encyclopedia of Energy, Natural Resource, and Environmental Economics. London: Elsevier Science

Ervin DE, Jussaume R (2014) Integrating social science into managing herbicide-resistant weeds and associated environmental impacts. Weed Sci 62:403-414

Goldberger J, Merrill J, Hurley T (2005) Bt corn farmer compliance with insect resistance management requirements in Minnesota and Wisconsin. AgBioForum 8:151-160

Health Canada (2013) Regulatory Directive DIR2013-04, Pesticide Resistance Management Labelling Based on Target Site/Mode of Action. http://www.hc-sc.gc.ca/cps-spc/pubs/ pest/_pol-guide/dir2013-04/index-eng.php. Accessed April 18,2016

Heap I (2016) International Survey of Herbicide Resistant Weeds. http://weedscience.org/. Accessed April 19, 2016

Housenger J (2014) EPA's Perspective on Resistance Herbicide Resistance Summit II. http://wssa.net/wp-content/uploads/ Composite\%20Summit\%20II\%20Presentations\%20Final. pdf. Accessed April 18, 2016

Livingston M, Fernandez-Cornejo J, Unger J, Osteen C, Schimmelpfennig D, Park T, Lambert D (2015) The 
economics of glyphosate resistance management in corn and soybean production. ERR-184. Washington, D.C.: U.S. Department of Agriculture, Economic Research Service. 45 p Matten SR (1997) Pesticide Resistance Activities of the U.S. Environmental Protection Agency. Resistant Pest Management Newsletter 9:3-5. http://whalonlab.msu.edu/wpcontent/uploads/2012/06/9_1.pdf. Accessed April 18, 2016

Matten SR (2003) U.S. EPA's voluntary labeling guidelines for pesticide resistance management based on rotation of mode of action. Pestic Outlook 14:111-113

Matten SR, Head GP, Quemada HD (2008) How government regulation can help or hinder the integration of $\mathrm{Bt}$ crops within IPM programs. Pages 27-39 in Romeis J, Shelton AM, Kennedy GG, eds. Integration of Insect-Resistant Genetically Modified Crop with IPM Programs. New York, NY: Springer Mitchell PD (2011) Economic assessment of the benefits of chloro-s-triazine herbicides to US corn, sorghum, and sugarcane producers. University of Wisconsin Agricultural and Applied Economics Staff Paper 564. Madison, WI: University of Wisconsin. $48 \mathrm{p}$

Monsanto (2015) Roundup Ready Plus ${ }^{\circledR}$ Challenge to Demonstrate Effectiveness and Value of Residual Herbicide Programs in Soybeans. http://news.monsanto.com/press-release/ products/roundup-ready-plus-challenge-demonstrateeffectiveness-and-value-residual-her. Accessed April 19, 2016

National Cotton Council (2016) History of the Eradication Program. http://www.cotton.org/tech/pest/bollweevil/ eradication2.cfm. Accessed April 18, 2016

Norsworthy JK, Smith KL, Scott RC, Gbur EE (2009) Consultant perspectives on weed management needs in Arkansas cotton. Weed Tech 21:825-831

Norsworthy JK, Ward SM, Shaw DR, Llewellyn RS, Nichols RL, Webster TM, Bradley KW, Frisvold G, Powles SB, Burgos NR, Witt WW, Barrett M (2012) Reducing the risks of herbicide resistance: best management practices and recommendations. Weed Sci 60(sp1):31-62

North American Invasive Species Network (2016) National CWMA Map. http://www.naisn.org/cwmamap/. Accessed April 16, 2016

Northeastern Illinois Invasive Plant Partnership (2016) What is a CWMA? http://niipp.net/what- cwma. Accessed April 18, 2016

Porpiglia P, Porter R, Thomas W, Landes A, Armel G, Beffa R, Stek H, Kleven T, Cotie A, Patzoldt W, Vail G, Kaundun D, Miller B, Glasgow L. (2014) HPPD-Inhibitor Resistance Stewardship: The Perspective of the HRAC HPPD-Inhibitor Working Group. http://hracglobal.com/pdfs/hppd $\% 20$ fact\%20sheet.pdf. Accessed April 18, 2016

Prokopy LS, Floress K, Klothor-Weinkauf D, Baumgart-Getz A (2008) Determinants of agricultural best management practice adoption: evidence form the literature. J Soil Water Conserv 63:300-311

Reimer AP, Klothor-Weinkauf D, Prokopy LS (2012) The influence of perceptions of practices characteristics: an examination of agricultural best management practice adoption in two Indiana watersheds. J Rural Studies 28:118-128

Reimer AP, Thompson AW, Prokopy LS (2011) The multidimensional nature of environmental attitudes among farmers in Indiana: implications for conservation adoption. Agric Hum Values 29:29-40

Riar DS, Norsworthy JK, Steckel LE, Stephenson DO IV, Bond JA (2013) Consultant perspectives on weed management needs in midsouthern United States cotton: a follow-up survey. Weed Technol 27:778-787

Segerson K (2013) When is reliance on voluntary approaches in agriculture likely to be effective? Appl Econ Perspect Policy 35:565-592

Shaner DL, Beckie HJ (2014) The future for weed control and technology. Pest Manag Sci 70:1329-1339

Shaner DL, ed (2014) Herbicide Handbook. 10th edn. Champaign, IL: Weed Science Society of America. Pp 11-15

Sheeder RJ, Lynne GD (2011) Empathy-conditioned conservation: walking in the shoes of others as a conservation farmer. Land Econ 87:433-452

Shields EJ, Dauer JT, VanGessel MJ, Neumann G (2006) Horseweed (Conyza canadensis) seed collected in the planetary boundary layer. Weed Sci 54:1063-1067

Sosnoskie LM, Webster TM, Kichler JM, MacRae AW, Grey T, Culpepper AS (2012) Pollen-mediated dispersal of glyphosateresistance in Palmer amaranth under field conditions. Weed Sci 60:366-373

Soteres J, Everman W, Glasgow L, Ingegneri L, Schroeder J, Shaw D, Stachler J, Tardif F (2011) Lesson 4: Scouting After a Herbicide Application and Confirming Herbicide Resistance. http://wssa.net/herbicide-resistance/agronomic-crop-modulesdownload/. Accessed April 18, 2016

State of Delaware (2016) Noxious Weeds. http://dda.delaware. gov/plantind/noxious.shtml. Accessed April 18, 2016

Thompson GD, Head G (2001) Implications of regulating insect resistance management. Am Entomol 47:6-10

U.S. Congress (2010) Are "Superweeds" an Outgrowth of USDA Biotech Policy? (Part II). https://www.gpo.gov/fdsys/ pkg/CHRG-11 hhrg65649/html/CHRG-111 hhrg65649. htm. Accessed April 18, 2016

[USDA] U.S. Department of Agriculture (2016a) Natural Resources Conservation Service (NRCS) Overview. http:// www.usda.gov/wps/portal/usda/usdahome? contentid=NRCS_ Agency_Splash.xml. Accessed April 18, 2016

[USDA] U.S. Department of Agriculture (2016b) About NRCS. http://www.nrcs.usda.gov/wps/portal/nrcs/main/national/ about/. Accessed April 18, 2016

[USDA] U.S. Department of Agriculture (2016c) 2015 CSP Enhancement Activity Job Sheets. http://www.nrcs.usda.gov/ $\mathrm{wps} / \mathrm{portal} / \mathrm{nrcs} /$ detailfull/national/programs/financial/csp/? cid=stelprd b1265825. Accessed April 19, 2016

[USDA] U.S. Department of Agriculture (2016d) 2014 Farm Bill-Conservation Stewardship Program-NRCS. http:// www.nrcs.usda.gov/wps/portal/nrcs/detail/national/programs/ financial/csp/. Accessed April 19, 2016

[USDA] U.S. Department of Agriculture (2016e) Environmental Quality Incentives Program. http://www.nrcs.usda.gov/ wps/portal/nrcs/main/ky/programs/financial/eqip/. Accessed April 18, 2016

[USDA] U.S. Department of Agriculture (2016f) FY 2015 EQIP Conservation Activity Plan (CAP). http://www.nrcs.usda.gov/ wps/portal/nrcs/detail/national/programs/financial/eqip/? cid+stelprdb1262227. Accessed April 19, 2016

[USDA] U.S. Department of Agriculture (2016g) Conservation Innovation Grants. http://www.nrcs.usda.gov/wps/portal/nrcs/ main/national/programs/financial/cig/. Accessed April 18, 2016

[USDA] U.S. Department of Agriculture (2016h) Frequently Asked Question Biotech Yield Endorsement. http://www.rma. usda.gov/help/faq/bye.html. Accessed April 18, 2016

Barrett et al.: Incentives/regulations for HRM 
Volkmann K (2010) Monsanto offers millions in rebates to farmers. St. Louis Business Journal. October 19.

Weirich JW, Shaw DR, Owen MD, Dixon PM, Weller SC, Young BG, Wilson RG, Jordan DL (2011) Benchmark study on glyphosate-resistant cropping systems in the United States. Part 5: Effects of glyphosate-based weed management programs on farm-level profitability. Pest Manag Sci 67:781-784

[WSSA] Weed Science Society of America (2014) Herbicide Resistance Summit II (10 September 2014, Washington, DC). http://wssa.net/wssa/weed/resistance-summit-ii/. Accessed April 19, 2016

Received September 30, 2015, and approved April 26, 2016.

Associate Editor for this paper: Sarah Ward, Colorado State University.

640 - Weed Science 64, Special Issue 2016 